\title{
Quantity Calculus, Fundamental Constants, and SI Units
}

\author{
Barry N. Taylor \\ Scientist Emeritus \\ National Institute of Standards and Technology, \\ Gaithersburg, MD 20899-8420, USA \\ barry.taylor@nist.gov
}

\begin{abstract}
A revised International System of Units (SI) is expected to be established by the 26th General Conference on Weights and Measures when it convenes in November 2018 and to be put into practice starting on 20 May 2019, World Metrology Day. In consequence, the article published in this journal in 2011, “The Current SI Seen from the Perspective of the Proposed New SI," is updated in this paper, which provides an opportunity to again demonstrate the usefulness of the quantity calculus in dealing with quantities and units. The quantity calculus and the seven defining constants of the current and revised SI are reviewed, and expressions for the seven current and revised SI base units are given. Relationships between the magnitudes of revised and current SI units and expressions for the numerical values of current SI defining constants expressed in revised SI units are also obtained using the quantity calculus.
\end{abstract}

Key words: fundamental constants; International System of Units; quantity calculus; SI; SI defining constants.

Accepted: May 18, 2018

Published: June 5, 2018

https://doi.org/10.6028/jres.123.008

\section{Introduction}

A paper we published in this journal in 2011 shows in detail how, with the aid of the quantity calculus, the current International System of Units (SI) can be viewed as being founded on seven reference quantities, now called defining constants [1, 2]. The motivation for that paper was the likely adoption in the not-too-distant future of a revised SI (referred to as the "new SI" at the time) explicitly based on seven defining constants, three of which would be the same as for the current SI but four of which would be different. Sufficient progress has now been made in the required experimental work that such a revised SI is now expected to be established by the 26th General Conference on Weights and Measures (CGPM) when it convenes 13-18 November 2018 and which will come into effect on 20 May 2019, World Metrology Day [3-12].

In light of this development, we update the 2011 paper making extensive use of the quantity calculus, thereby demonstrating again the utility of this approach in dealing with quantities, fundamental constants, numerical values, and units. We begin by reviewing the quantity calculus and the seven defining constants of the current SI and presenting expressions for the seven current SI base units in terms of the current SI defining constants. This is followed by a similar discussion of the defining constants of the revised SI and presentation of the expressions for the seven revised SI base units in terms of the revised SI defining constants. We then show how the quantity calculus can be used to obtain relationships between the magnitudes of revised SI units and the magnitudes of their corresponding current SI units, and the relationships between the values of the current SI defining constants expressed in their revised SI units and their exactly known current SI values. 


\section{Quantity Calculus}

In the quantity calculus, unit symbols are treated as normal algebraic quantities. As discussed in Ref. [1], the value of a quantity $A$ is generally expressed as

$$
A=\{A\}_{\mathrm{U}} \mathrm{U},
$$

where $\{A\}_{U}$ is the numerical value of the quantity $A$ when the value of $A$ is expressed in the unit $U$. This equation can be rewritten as

$$
\mathrm{U}=\frac{A}{\{A\}_{\mathrm{U}}}
$$

Equation (2) implies that if $A$ is an unchanging, or invariant, quantity, such as a fundamental constant like the speed of light in vacuum $c$, the unit $U$ can be defined as the quotient of the invariant quantity $A$ and an adopted fixed (that is, exact) numerical value.

Another important concept is that the value of a quantity is an inherent property of the quantity-it does not change when the value of the quantity is expressed in different units, only its numerical value changes. Consider a fundamental constant $C$ the value of which is expressed in two different units $(\mathrm{U})_{1}$ and $(\mathrm{U})_{2}$ and hence with two different numerical values $\{C\}_{1}$ and $\{C\}_{2}$ :

$$
C=\{C\}_{1}(\mathrm{U})_{1}=\{C\}_{2}(\mathrm{U})_{2} \text {, }
$$

implying

$$
\frac{(\mathrm{U})_{2}}{(\mathrm{U})_{1}}=\frac{\{C\}_{1}}{\{C\}_{2}}
$$

The ratio of the two different units is opposite to that of the two different numerical values. [Here and in similar cases throughout the paper, unit symbols are in Roman (upright) font in parentheses and numericalvalue symbols are in italic font in curly brackets.] Example: An article states that the speed of light $c$ is approximately 1 billion, 80 million kilometers per hour, or three hundred million meters per second. Thus, $c=\left\{1.080 \times 10^{9}\right\}_{\mathrm{km} / \mathrm{h}} \mathrm{km} / \mathrm{h}=\left\{300 \times 10^{6}\right\}_{\mathrm{m} / \mathrm{s}} \mathrm{m} / \mathrm{s}$, or $(\mathrm{m} / \mathrm{s}) /(\mathrm{km} / \mathrm{h})=\left\{1.080 \times 10^{9}\right\}_{\mathrm{km} / \mathrm{h}} /\left\{300 \times 10^{6}\right\}_{\mathrm{m} / \mathrm{s}}=3.6$; the unit $\mathrm{m} / \mathrm{s}$ is 3.6 times larger than the unit $\mathrm{km} / \mathrm{h}$, and the numerical value $\{c\}_{\mathrm{m} / \mathrm{s}}$ is $1 /(3.6)$ times the numerical value $\{c\}_{\mathrm{km} / \mathrm{h}}$.

\section{The Current SI}

\subsection{Current SI Defining Constants}

As discussed in Ref. [1] and in accordance with Eq. (2), the current SI can be viewed as being defined by assigning an exact numerical value to each of seven defining constants when the value of each is expressed in its respective unit. The seven defining constants of the current SI are the unperturbed groundstate hyperfine transition frequency of the cesium 133 atom $\Delta v_{\mathrm{Cs}}$, SI unit hertz, Hz; speed of light in vacuum $c$, SI unit meter per second, $\mathrm{m} \mathrm{s}^{-1}$; mass of the international prototype of the kilogram $m(\mathcal{K})$, SI unit kilogram, kg; magnetic constant (permeability of vacuum) $\mu_{0}$, SI unit henry per meter, $\mathrm{H} \mathrm{m}^{-1}$; triple point of water $T_{\mathrm{TPW}}$, SI unit kelvin, K; molar mass of carbon $12, M\left({ }^{12} \mathrm{C}\right)$, SI unit kilogram per mole, $\mathrm{kg} \mathrm{mol}^{-1}$; and luminous efficacy of monochromatic radiation of frequency $540 \times 10^{12} \mathrm{~Hz}, K_{\mathrm{cd}}$, SI unit lumen per watt, $\operatorname{lm~} \mathrm{W}^{-1}$ [1, 2]. (In terms of base units, $\mathrm{Hz}$ is a special symbol for the reciprocal second, $\mathrm{s}^{-1}$, but only for 
expressing the frequency of a periodic phenomenon; $\mathrm{H}$ is a special symbol for $\mathrm{kg} \mathrm{m} \mathrm{s}^{-2} \mathrm{~A}^{-2}$, where $\mathrm{A}$ is the symbol for the ampere; $\operatorname{lm}$ is a special symbol for the candela steradian, $c d s r$, where $\mathrm{sr}=\mathrm{m}^{2} / \mathrm{m}^{2}=1$; and W is a special symbol for $\mathrm{J} \mathrm{s}^{-1}$, where the joule, $\mathrm{J}$, is a special name and symbol for $\mathrm{kg} \mathrm{m}^{2} \mathrm{~s}^{-2}$, implying that $\operatorname{lm~} \mathrm{W}^{-1}=\mathrm{cd} \mathrm{sr} \mathrm{W}^{-1}=\mathrm{cd} \mathrm{sr} \mathrm{kg}^{-1} \mathrm{~m}^{-2} \mathrm{~s}^{3}$.)

The units defined by these seven current SI defining constants and their numerical values when expressed in those units are, based on Eq. (2),

$$
\begin{aligned}
& \mathrm{Hz}=\frac{\Delta v_{\mathrm{Cs}}}{9192631770}, \\
& \mathrm{~m} \mathrm{~s}^{-1}=\frac{c}{299792458} \text {, } \\
& \mathrm{kg}=\frac{m(\mathcal{K})}{1}, \\
& \mathrm{H} \mathrm{m}^{-1}=\frac{\mu_{0}}{4 \pi \times 10^{-7}} \text {, } \\
& \mathrm{K}=\frac{T_{\mathrm{TPW}}}{273.16} \text {, } \\
& \mathrm{kg} \mathrm{mol}^{-1}=\frac{M\left({ }^{12} \mathrm{C}\right)}{12 \times 10^{-3}}, \\
& \operatorname{lm} \mathrm{W}^{-1}=\frac{K_{\mathrm{cd}}}{683} \text {. }
\end{aligned}
$$

However, because the international prototype of the kilogram is a $90 \%$ Pt-10 \% Ir cylinder about $39 \mathrm{~mm}$ in diameter and height and hence is a material artifact, unlike the other six defining constants, $m(\mathcal{K})$ is not really [or "fundamentally"] an invariant quantity. Nevertheless, it is treated as such, because ever since the mass of the international prototype was adopted by the 1st CGPM in 1889 as the unit of mass, by definition $m(K)$ has been always $1 \mathrm{~kg}$ exactly [2].

\subsection{Current SI Base Units}

Equations (5a)-(5g) show that the seven current SI defining constants $\Delta v_{\mathrm{Cs}}, c, m(\mathcal{K}), \mu_{0}, T_{\mathrm{TPW}}, M\left({ }^{12} \mathrm{C}\right)$, and $K_{\mathrm{cd}}$ directly define their respective units $\mathrm{Hz}, \mathrm{m} \mathrm{s}^{-1}, \mathrm{~kg} \mathrm{H} \mathrm{m}^{-1}, \mathrm{~K}, \mathrm{~kg} \mathrm{~mol}^{-1}$, and $\mathrm{lm} \mathrm{W}^{-1}$. Additionally, these seven defining constants taken together define the SI base units s, m, kg, A, K, mol, and cd. This can be seen from an examination of Eqs. (5a)-(5g) in the order given.

Because $\mathrm{Hz}=\mathrm{s}^{-1}$, Eq. (5a) defines the second, s. Equation (5b) defines $\mathrm{m} \mathrm{s}^{-1}$, hence in combination with Eq. (5a) it defines the meter, m. Equation (5c) defines the kilogram, kg. Because, in Eq. (5d), $\mathrm{H} \mathrm{m}^{-1}=\mathrm{kg} \mathrm{m} \mathrm{s}^{-2} \mathrm{~A}^{-2}$, together with Eqs. (5a), (5b), and (5c), it defines the ampere, A. Equation (5e) defines the kelvin, K. Equation (5f) defines the mole, mol. Finally, noting that in Eq. (5g) the lumen, $\mathrm{lm}$, equals cd sr and $\mathrm{W}^{-1}=\mathrm{J}^{-1} \mathrm{~s}=\mathrm{kg}^{-1} \mathrm{~m}^{-2} \mathrm{~s}^{3}$, in combination with Eqs. (5a), (5b), and (5c), it defines the candela, cd. In consequence, we obtain the following seven expressions for the seven base units s, $\mathrm{m}, \mathrm{kg}, \mathrm{A}$, $\mathrm{K}$, mol, and cd, where here and elsewhere the ellipsis (three dots) indicates an indefinite number of digits:

$$
\mathrm{s}=\frac{9192631770}{\Delta v_{\mathrm{Cs}}}
$$




$$
\begin{gathered}
\mathrm{m}=\frac{9192631770}{299792458} \frac{c}{\Delta v_{\mathrm{Cs}}}=30.6633189 \ldots \frac{c}{\Delta v_{\mathrm{Cs}}}, \\
\mathrm{kg}=\frac{m(\mathcal{K})}{1}, \\
\mathrm{~A}=\left(\frac{4 \pi \times 10^{-7}}{(9192631770)(299792458)} \frac{m(\mathcal{K}) c \Delta v_{\mathrm{Cs}}}{\mu_{0}}\right)^{1 / 2}=6.7526563 \ldots \times 10^{-13}\left(\frac{m(\mathcal{K}) c \Delta v_{\mathrm{Cs}}}{\mu_{0}}\right)^{1 / 2}, \\
\mathrm{~K}=\frac{T_{\mathrm{TPW}}}{273.16}, \\
\mathrm{~mol}=12 \times 10^{-3} \frac{m(\mathcal{K})}{M\left({ }^{12} \mathrm{C}\right)}, \\
\mathrm{cd}=\frac{1}{(9192631770)(299792458)^{2} 683} m(\mathcal{K}) c^{2} \Delta v_{\mathrm{Cs}} K_{\mathrm{cd}}=1.7721399 \ldots \times 10^{-30} m(\mathcal{K}) c^{2} \Delta v_{\mathrm{Cs}} K_{\mathrm{cd}} .
\end{gathered}
$$

\section{4. $\quad$ Revised SI}

\subsection{Revised SI Defining Constants}

Like the current SI, the revised SI is based on seven exactly known defining constants, but three are the same as in the current SI: $\Delta v_{\mathrm{Cs}}, c$, and $K_{\mathrm{cd}}$. The other four are the Planck constant $h$, SI unit J s; elementary charge $e$, SI unit C; Boltzmann constant $k$, SI unit $\mathrm{J} \mathrm{K}^{-1}$; and Avogadro constant $N_{\mathrm{A}}$, SI unit $\mathrm{mol}^{-1}[6,7]$. (As already indicated, in terms of base units, $\mathrm{J}$ is a special symbol for $\mathrm{kg} \mathrm{m}^{2} \mathrm{~s}^{-2}$; similarly, the coulomb, symbol C, is a special name and symbol for A s.)

The exact numerical values of these four revised SI defining constants were determined by the Committee on Data for Science and Technology (CODATA) Task Group on Fundamental Constants and are based on the CODATA 2017 Special Adjustment of fundamental constants carried out by the Task Group in the summer of 2017 using current SI units [6, 7]. As stipulated by the International Committee for Weights and Measures (CIPM), the adjustment considered all relevant data published or accepted for publication by 1 July 2017 [8]. The CODATA numerical values were subsequently adopted by the CIPM at its 106th meeting in October 2017 [9]. However, these values will not become official until formally adopted by the 26th CGPM when it meets in November 2018; until then, they should be viewed as proposed values.

The units that these seven revised SI defining constants define and their numerical values when expressed in those units based on Eq. (2) are [6, 7]

$$
\begin{aligned}
& \mathrm{Hz}=\frac{\Delta v_{\mathrm{Cs}}}{9192631770} \text { (no change), } \\
& \mathrm{m} \mathrm{s}^{-1}=\frac{c}{299792458} \text { (no change), } \\
& \mathrm{J} \mathrm{s}=\frac{h}{6.62607015 \times 10^{-34}} \text { (new), } \\
& \mathrm{J} \mathrm{K}^{-1}=\frac{k}{1.380649 \times 10^{-23}} \text { (new), }
\end{aligned}
$$




$$
\begin{aligned}
& \mathrm{C}=\frac{e}{1.602176634 \times 10^{-19}} \text { (new), } \\
& \mathrm{mol}^{-1}=\frac{N_{\mathrm{A}}}{6.02214076 \times 10^{23}} \text { (new), } \\
& \operatorname{lm~\mathrm {W}^{-1}}=\frac{K_{\mathrm{cd}}}{683} \text { (no change). }
\end{aligned}
$$

\subsection{Revised SI Base Units}

Equations (7a)-(7g) show that the seven revised SI defining constants $\Delta v_{\mathrm{Cs}}, c, h, e, k, N_{\mathrm{A}}$, and $K_{\mathrm{cd}}$ directly define their respective units $\mathrm{Hz}, \mathrm{m} \mathrm{s}^{-1}, \mathrm{~J} \mathrm{~s}, \mathrm{C}, \mathrm{J} \mathrm{K}^{-1}$, $\mathrm{mol}^{-1}$, and $\mathrm{lm} \mathrm{W}^{-1}$. Nevertheless, as in the case of the seven current SI defining constants, these seven revised SI defining constants taken together define the SI base units s, m, kg, A, K, mol, and cd. This can be seen from an examination of Eqs. (7a)-(7g) in the order given.

Because $\mathrm{Hz}=\mathrm{s}^{-1}$, Eq. (7a) defines the second, s. Equation (7b) defines $\mathrm{m} \mathrm{s}^{-1}$, hence, in combination with Eq. (7a), it defines the meter, $\mathrm{m}$. Equations (7a) and (7c) in combination define the joule, J, and because $\mathrm{J}=\mathrm{kg} \mathrm{m}^{2} \mathrm{~s}^{-2}$, the three equations (7a), (7b), and (7c) together define the kilogram, kg. Because $\mathrm{C}=\mathrm{A}$ s, Eq. (7a) in combination with Eq. (7d) define the ampere, A. Equations (7a) and (7c) in combination define J; thus, the two equations together with Eq. (7e) define the kelvin, K. Equation (7f) defines the mole, mol. Finally, because $\mathrm{lm}=\mathrm{cd}$ sr and $\mathrm{W}=\mathrm{J} \mathrm{s}^{-1}$, Eqs. (7a), (7d), and (7g) together define the candela, cd. The end result is the following seven expressions for the seven base units s, m, kg, A, K, mol, and cd:

$$
\begin{gathered}
\mathrm{s}=\frac{9192631770}{\Delta v_{\mathrm{Cs}}}, \\
\mathrm{m}=\frac{9192631770}{299792458 \frac{c}{\Delta v_{\mathrm{Cs}}}}=30.6633189 \ldots \frac{c}{\Delta v_{\mathrm{Cs}}}, \\
\mathrm{kg}=\frac{(299792458)^{2} \times 10^{34}}{(6.62607015)(9192631770)} \frac{h \Delta v_{\mathrm{Cs}}}{c^{2}}=1.4755213 \ldots \times 10^{40} \frac{h \Delta v_{\mathrm{CS}}}{c^{2}}, \\
\mathrm{~A}=\frac{10^{19}}{(1.602176634)(9192631770)} e \Delta v_{\mathrm{Cs}}=6.7896868 \ldots \times 10^{8} e \Delta v_{\mathrm{Cs}}, \\
\frac{1.380649 \times 10^{11}}{(6.62607015)(9192631770)} \frac{h \Delta v_{\mathrm{Cs}}}{k}=2.2666652 \ldots \frac{h \Delta v_{\mathrm{Cs}}}{k}, \\
\mathrm{~mol}=\frac{6.02214076 \times 10^{23}}{N_{\mathrm{A}}},
\end{gathered}
$$

\footnotetext{
${ }^{1}$ The ampere A is the SI base unit for electric current and the volt $\mathrm{V}$, a special name and symbol for $\mathrm{kg} \mathrm{m}^{2} \mathrm{~s}^{-3} \mathrm{~A}^{-1}$, is the SI derived unit for electric potential difference, or voltage. In practice, voltage is measured using the Josephson effect and requires the value of the Josephson constant $K_{\mathrm{J}}=2 e / h$. The numerical values of the revised SI defining constants $e$ and $h$ contain 10 and 9 digits, respectively, and yield the exact numerical value $483597848416983.63 \ldots$ for $K_{\mathrm{J}}$. The relative standard uncertainty of Josephsoneffect measurements of voltage can be as small as a few parts in $10^{12}$ [13]; although rounding $K_{\mathrm{J}}$ to 13 digits ensures that the error introduced by using such a truncated value is negligible, it is noteworthy that 13 digits is 3 more than that of $e$ and 4 more than that of h. Similar considerations apply in other cases.
} 


$$
\mathrm{cd}=\frac{10^{34}}{(6.62607015)(9192631770)^{2} 683}\left(\Delta v_{\mathrm{Cs}}\right)^{2} h K_{\mathrm{cd}}=2.6148304 \ldots \times 10^{10}\left(\Delta v_{\mathrm{Cs}}\right)^{2} h K_{\mathrm{cd}} .
$$

The important role of the defining constant for the second, $\Delta v_{\mathrm{Cs}}$, is apparent.

\section{Relationships Between Revised SI and Current SI Units}

We show in this section how the quantity calculus can be used to obtain useful relationships between the magnitudes of revised SI units and the magnitudes of the corresponding current SI units. Consistency of the revised SI with the current SI is a CGPM requirement [4] and these relationships enable such consistency to be demonstrated. Paragraphs (i)-(v) below explain the specific notation used, but for the convenience of the reader we first recall the notation and nomenclature that has become common in the field of fundamental constants and metrology.

The standard uncertainty $u(Q)$ of the value of quantity $Q$ is the estimated standard deviation of the value. It is usually given as two digits in parentheses at the end of the value. For example, consider the recommended value of the Planck constant $h$ from the regular CODATA 2014 quadrennial adjustment of the values of the constants $[14,15]$. That value is $h=6.626070040(81) \times 10^{-34} \mathrm{~J} \mathrm{~s}$, where "(81)" is a concise way of indicating that the standard uncertainty $u(h)$ of the value of $h$ is $0.000000081 \times 10^{-34} \mathrm{~J} \mathrm{~s}$. The relative standard uncertainty of $Q$ is defined as $u_{\mathrm{r}}(Q)=u(Q) / Q$, which means that for the Planck constant, $u_{\mathrm{r}}(h)$ equals the above value of $u(h)$ divided by $6.626070040 \times 10^{-34} \mathrm{~J} \mathrm{~s}$ or $1.2 \times 10^{-8}$. In text, $u_{\mathrm{r}}$ is usually given in square brackets following the value; thus, $h=6.626070040(81) \times 10^{-34} \mathrm{~J} \mathrm{~s}\left[1.2 \times 10^{-8}\right]$.

(i) A unit symbol in parentheses with a subscript "cur" means it is a unit of the current SI; if the subscript is "rev" it is a unit of the revised SI. Examples: $(\mathrm{kg})_{\text {cur }},(\mathrm{K})_{\text {rev. }}$ However, a comparison of Eqs. (6a) and (6b) with Eqs. (8a) and (8b) shows that the second, s, and meter, m, are the same in the current SI and revised SI; hence, there is no need to distinguish between them.

(ii) A constant in curly brackets with subscript "cur" means the numerical value of that constant resulting from the CODATA 2017 Special Adjustment since that adjustment was carried out using current SI units; if the subscript is "rev" it means the numerical value of that constant when expressed in its revised SI unit. Examples: $\{h\}_{\text {cur }},\{e\}_{\text {cur }},\{k\}_{\text {cur, }}$ and $\left\{N_{\mathrm{A}}\right\}_{\text {cur }}$ mean the CODATA 2017 Special Adjustment numerical values as given in Table 2 of Ref. [6]; $\{h\}_{\text {rev }},\{e\}_{\text {rev }},\{k\}_{\text {rev }}$, and $\left\{N_{\mathrm{A}}\right\}_{\text {rev }}$ mean the exact numerical values given in Table 3 of Ref. [6] and in Eqs. (7c), (7d), (7e), and (7f), respectively. We also keep in mind that $\{m(\mathcal{K})\}_{\mathrm{cur}}=1,\left\{\mu_{0}\right\}_{\mathrm{cur}}=4 \pi \times 10^{-7},\left\{T_{\mathrm{TPW}}\right\}_{\mathrm{cur}}=273.16$, and $\left\{M\left({ }^{12} \mathrm{C}\right)\right\}_{\mathrm{cur}}=12 \times 10^{-3}$ as given in Eqs. (5c), (5d), (5e), and (5f), respectively.

(iii) If the constant in curly brackets with subscript "cur" is a combination of constants it is the CODATA 2017 Special Adjustment value of the combination, including its uncertainty, that is relevant because the individual constants of the combination are correlated. Example: $\left\{h / e^{2}\right\}_{\text {cur }}$ means the CODATA 2017 Special Adjustment numerical value of the combination.

(iv) If the constant in curly brackets with subscript "rev" is a combination of two or more of the exactly known revised SI defining constants $h, e, k$, and $N_{\mathrm{A}}$, then the numerical value is simply that of the combination and has no uncertainty. Example: from Eqs. (7c) and (7f), $\left\{N_{\mathrm{A}} h\right\}_{\text {rev }}$ means the exact number $6.02214076 \times 10^{23} \times 6.62607015 \times 10^{-34}=3.9903127128934314 \times 10^{-11}$.

(v) The revised SI defining constants $h, e, k$, and $N_{\mathrm{A}}$ have no uncertainty. Thus, the relative standard uncertainty $u_{\mathrm{r}}$ of the ratio of the numerical value of one of these constants and the numerical value of the same constant expressed in current SI units is that of the one expressed in current SI units. This also applies if the ratio is for a combination of constants. (In general, if the quantities $Q, X$, and $Y$ are related by $Q=X / Y$ and $X$ is exactly known, then the relative standard uncertainty of $Q$ is equal to the relative standard 
uncertainty of $Y$; if $Y$ is exactly known, the relative standard uncertainty of $Q$ is equal to that of $X$.) Examples: $u_{\mathrm{r}}$ of $\{h\}_{\text {cur }} /\{h\}_{\text {rev }}$ equals that of $\{h\}_{\text {cur }} ; u_{\mathrm{r}}$ of $\left\{h / e^{2}\right\}_{\text {rev }} /\left\{h / e^{2}\right\}_{\text {cur }}$ equals that of $\left\{h / e^{2}\right\}_{\text {cur. }}{ }^{2}$

\subsection{Base Unit Relationships}

As pointed out in paragraph (i) above, s and $\mathrm{m}$ are unchanged in the revised SI, thus one can write for the ratio of the magnitude of the revised SI second to the magnitude of the current SI second,

$$
\frac{(\mathrm{s})_{\mathrm{rev}}}{(\mathrm{s})_{\mathrm{cur}}}=1 \text {, }
$$

and similarly, for the meter,

$$
\frac{(\mathrm{m})_{\mathrm{rev}}}{(\mathrm{m})_{\mathrm{cur}}}=1 .
$$

However, the equality between the revised and current unit magnitudes of $\mathrm{s}$ and $\mathrm{m}$ is not true of kg, A, K, mol, and cd, which are the five other base units and which we now address. For the kilogram we start by writing, based on Eq. (3) and the fact that the unit of the Planck constant $h$ is $\mathrm{J} \mathrm{s}=\mathrm{kg} \mathrm{m}^{2} \mathrm{~s}^{-1}$,

$$
h=\{h\}_{\text {cur }}(\mathrm{kg})_{\text {cur }} \mathrm{m}^{2} \mathrm{~s}^{-1}=\{h\}_{\text {rev }}(\mathrm{kg})_{\text {rev }} \mathrm{m}^{2} \mathrm{~s}^{-1},
$$

implying

$$
\frac{(\mathrm{kg})_{\mathrm{rev}}}{(\mathrm{kg})_{\mathrm{cur}}}=\frac{\{h\}_{\mathrm{cur}}}{\{h\}_{\mathrm{rev}}}
$$

This equation shows that the ratio of the magnitude of the revised SI kilogram to the magnitude of the current SI kilogram is equal to the ratio of the CODATA 2017 Special Adjustment numerical value of $h$ to the exactly defined revised SI numerical value of $h$. (These values are given in Tables 2 and 3 of Ref. [6], respectively, as are the corresponding values of $e, k$, and $N_{\mathrm{A}}$.)

The derivations of the ratios for $\mathrm{A}, \mathrm{K}, \mathrm{mol}$, and cd proceed in a similar manner. The unit of the elementary charge $e$ is $\mathrm{C}=\mathrm{A} \mathrm{s}$, thus

leading to

$$
e=\{e)_{\text {cur }}(\mathrm{A})_{\text {cur }} \mathrm{S}=\{e\}_{\text {rev }}(\mathrm{A})_{\text {rev }} \mathrm{S},
$$

$$
\frac{(\mathrm{A})_{\mathrm{rev}}}{(\mathrm{A})_{\mathrm{cur}}}=\frac{\{e\}_{\mathrm{cur}}}{\{e\}_{\mathrm{rev}}} .
$$

The unit of the Boltzmann constant $k$ is $\mathrm{J} \mathrm{K}^{-1}=\mathrm{kg} \mathrm{m}^{2} \mathrm{~s}^{-2} \mathrm{~K}^{-1}$, from which

$$
k=\{k\}_{\mathrm{cur}}(\mathrm{kg})_{\mathrm{cur}} \mathrm{m}^{2} \mathrm{~s}^{-2}\left(\mathrm{~K}^{-1}\right)_{\mathrm{cur}}=\{k\}_{\mathrm{rev}}(\mathrm{kg})_{\mathrm{rev}} \mathrm{m}^{2} \mathrm{~s}^{-2}\left(\mathrm{~K}^{-1}\right)_{\mathrm{rev}},
$$

resulting in

\footnotetext{
${ }^{2}$ If $Q=X / Y$ and $X$ and $Y$ are uncorrelated, based on the law of propagation of uncertainty as given in Eq. (10) of Ref. [16], the variance $u^{2}(Q)$ (square of the standard deviation) is

$u^{2}(Q)=\left(\frac{\partial Q}{\partial X}\right)^{2} u^{2}(X)+\left(\frac{\partial Q}{\partial Y}\right)^{2} u^{2}(Y)=\left(\frac{1}{Y}\right)^{2} u^{2}(X)+\left(\frac{-X}{Y^{2}}\right)^{2} u^{2}(Y)=\left(\frac{X}{Y}\right)^{2} \frac{u^{2}(X)}{X^{2}}+\left(\frac{X}{Y}\right)^{2} \frac{u^{2}(Y)}{Y^{2}}$,

or the relative variance is $\frac{u^{2}(Q)}{Q^{2}}=u_{\mathrm{r}}^{2}(Q)=u_{\mathrm{r}}^{2}(X)+u_{\mathrm{r}}^{2}(Y)$. Thus, if $X$ is exact $u_{\mathrm{r}}^{2}(X)=0$

and $u_{\mathrm{r}}(Q)=u_{\mathrm{r}}(Y)$. If $Y$ is exact $u_{\mathrm{r}}^{2}(Y)=0$ and $u_{\mathrm{r}}(Q)=u_{\mathrm{r}}(X)$.
} 
or, with the aid of Eq. (9c),

$$
\frac{(\mathrm{K})_{\mathrm{rev}}}{(\mathrm{K})_{\mathrm{cur}}}=\frac{\{k\}_{\mathrm{rev}}}{\{k\}_{\mathrm{cur}}} \frac{(\mathrm{kg})_{\mathrm{rev}}}{(\mathrm{kg})_{\mathrm{cur}}}
$$

and finally

$$
\frac{(\mathrm{K})_{\mathrm{rev}}}{(\mathrm{K})_{\mathrm{cur}}}=\frac{\{k\}_{\mathrm{rev}}}{\{k\}_{\mathrm{cur}}} \frac{\{h\}_{\mathrm{cur}}}{\{h\}_{\mathrm{rev}}},
$$

$$
\frac{(\mathrm{K})_{\mathrm{rev}}}{(\mathrm{K})_{\mathrm{cur}}}=\frac{\{k / h\}_{\mathrm{rev}}}{\{k / h\}_{\mathrm{cur}}}
$$

The unit of the Avogadro constant $N_{\mathrm{A}}$ is $\mathrm{mol}^{-1}$, therefore

implying

$$
N_{\mathrm{A}}=\left\{N_{\mathrm{A}}\right\}_{\mathrm{cur}}\left(\mathrm{mol}^{-1}\right)_{\text {cur }}=\left\{N_{\mathrm{A}}\right\}_{\text {rev }}\left(\mathrm{mol}^{-1}\right)_{\mathrm{rev}},
$$

$$
\frac{(\mathrm{mol})_{\mathrm{rev}}}{(\mathrm{mol})_{\mathrm{cur}}}=\frac{\left\{N_{\mathrm{A}}\right\}_{\mathrm{rev}}}{\left\{N_{\mathrm{A}}\right\}_{\mathrm{cur}}}
$$

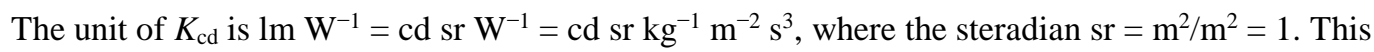
means that, like $\mathrm{s}$ and $\mathrm{m}$, there is no need to distinguish between (sr) cur $_{\text {and }}(\mathrm{sr})_{\text {rev }}$ and for simplicity sr can be used. This is also the case for the numerical value of $K_{\mathrm{cd}}$ since $\left\{K_{\mathrm{cd}}\right\}_{\mathrm{rev}}=\left\{K_{\mathrm{cd}}\right\}_{\mathrm{cur}}=683$ and $\left\{K_{\mathrm{cd}}\right\}$ suffices. We can therefore write

or

$$
K_{\mathrm{cd}}=\left\{K_{\mathrm{cd}}\right\}(\mathrm{cd})_{\mathrm{cur}} \mathrm{sr}\left(\mathrm{kg}^{-1}\right)_{\mathrm{cur}} \mathrm{m}^{-2} \mathrm{~s}^{3}=\left\{K_{\mathrm{cd}}\right\}(\mathrm{cd})_{\mathrm{rev}} \mathrm{sr}\left(\mathrm{kg}^{-1}\right)_{\mathrm{rev}} \mathrm{m}^{-2} \mathrm{~s},
$$

which becomes with the aid of Eq. (9c),

$$
\frac{(\mathrm{cd})_{\mathrm{rev}}}{(\mathrm{cd})_{\mathrm{cur}}}=\frac{(\mathrm{kg})_{\mathrm{rev}}}{(\mathrm{kg})_{\mathrm{cur}}}
$$

$$
\frac{(\mathrm{cd})_{\mathrm{rev}}}{(\mathrm{cd})_{\mathrm{cur}}}=\frac{\{h\}_{\mathrm{cur}}}{\{h\}_{\mathrm{rev}}} .
$$

It is noteworthy that because of the dependence of the unit of $K_{\mathrm{cd}}$ on $\mathrm{kg}$, even though the numerical value of $K_{\mathrm{cd}}$ is the same in the revised SI as in the current SI, (cd) $)_{\text {rev }}$ differs from (cd) $)_{\text {cur. }}$.

\subsection{Derived Unit Relationships}

For convenience and ease of understanding, certain units derived from the seven SI base units have been given special names and symbols. There are 22 such SI derived units, which include the familiar joule and volt with SI symbols $\mathrm{J}$ and $\mathrm{V}$ used to express values of energy and electric potential difference, and perhaps the less familiar unit of catalytic activity, the katal, SI symbol kat. These are listed in Table 3 of Ref. [2], which is the SI Brochure published by the International Bureau of Weights and Measures (BIPM) located in Sèvres, France and is the definitive reference on the SI. These 22 units are combinations of base units and the relationships for the base-unit ratios $(\mathrm{U})_{\mathrm{rev}} /(\mathrm{U})_{\mathrm{cur}}$, where $\mathrm{U}$ is one of the seven units $\mathrm{s}, \mathrm{m}, \mathrm{kg}$, A, K, mol, or cd, are given in Eqs. (9a)-(9g). The derivation of the expressions for the 22 units is, therefore, straightforward and can be demonstrated by the example of the farad. The farad, symbol F, is the SI derived unit for expressing values of electric capacitance and is a special name and symbol for $\mathrm{kg}^{-1} \mathrm{~m}^{-2} \mathrm{~s}^{4} \mathrm{~A}^{2}$. With the aid of Eqs. (9c) and (9d), one can immediately write

$$
\frac{(\mathrm{F})_{\mathrm{rev}}}{(\mathrm{F})_{\mathrm{cur}}}=\frac{\left(\mathrm{kg}^{-1}\right)_{\mathrm{rev}}}{\left(\mathrm{kg}^{-1}\right)_{\mathrm{cur}}} \frac{\mathrm{m}^{-2}}{\mathrm{~m}^{-2}} \frac{\mathrm{s}^{4}}{\mathrm{~s}^{4}} \frac{\left(\mathrm{A}^{2}\right)_{\mathrm{rev}}}{\left(\mathrm{A}^{2}\right)_{\mathrm{cur}}}=\frac{\{h\}_{\mathrm{rev}}}{\{h\}_{\mathrm{cur}}} \frac{\left\{e^{2}\right\}_{\mathrm{cur}}}{\left\{e^{2}\right\}_{\mathrm{rev}}}=\frac{\left\{h / e^{2}\right\}_{\mathrm{rev}}}{\left\{h / e^{2}\right\}_{\mathrm{cur}}}
$$


The relationships for all 22 units can be concisely summarized as follows:

$$
\begin{gathered}
(\mathrm{U})_{\mathrm{rev}} /(\mathrm{U})_{\mathrm{cur}}=1 \text { for } \mathrm{U}=\mathrm{rad}, \mathrm{sr}, \mathrm{Hz}, \mathrm{Bq}, \mathrm{Gy} \text {, and Sv, } \\
(\mathrm{U})_{\mathrm{rev}} /(\mathrm{U})_{\mathrm{cur}}=\{h\}_{\mathrm{cur}} /\{h\}_{\mathrm{rev}} \text { for } \mathrm{U}=\mathrm{N}, \mathrm{Pa}, \mathrm{J}, \mathrm{W}, \mathrm{lm}, \mathrm{lx}, \\
(\mathrm{U})_{\mathrm{rev}} /(\mathrm{U})_{\mathrm{cur}}=\{e\}_{\mathrm{cur}} /\{e\}_{\mathrm{rev}} \text { for } \mathrm{U}=\mathrm{C}, \\
(\mathrm{U})_{\mathrm{rev}} /(\mathrm{U})_{\mathrm{cur}}=\{h / e\}_{\mathrm{cur}} /\{h / e\}_{\mathrm{rev}} \text { for } \mathrm{U}=\mathrm{V}, \mathrm{Wb}, \mathrm{T}, \\
(\mathrm{U})_{\mathrm{rev}} /(\mathrm{U})_{\mathrm{cur}}=\left\{h / e^{2}\right\}_{\mathrm{rev}} /\left\{h / e^{2}\right\}_{\mathrm{cur}} \text { for } \mathrm{U}=\mathrm{F}, \mathrm{S}, \\
(\mathrm{U})_{\mathrm{rev}} /(\mathrm{U})_{\mathrm{cur}}=\left\{h / e^{2}\right\}_{\mathrm{cur}} /\left\{h / e^{2}\right\}_{\mathrm{rev}} \text { for } \mathrm{U}=\Omega, \mathrm{H}, \\
(\mathrm{U})_{\mathrm{rev}} /(\mathrm{U})_{\mathrm{cur}}=\{k / h\}_{\mathrm{rev}} /\{k / h\}_{\mathrm{cur}} \text { for } \mathrm{U}={ }^{\circ} \mathrm{C}, \\
(\mathrm{U})_{\mathrm{rev}} /(\mathrm{U})_{\mathrm{cur}}=\left\{N_{\mathrm{A}}\right\}_{\mathrm{rev}} /\left\{N_{\mathrm{A}}\right\}_{\mathrm{cur}} \text { for } \mathrm{U}=\mathrm{kat} .
\end{gathered}
$$

Here rad, sr, Hz, Bq, Gy, and Sv are the symbols for the radian steradian, hertz, becquerel, gray, and sievert; N, Pa, J, W, lm, and lx for the newton, pascal, joule, watt, lumen, and lux; C for coulomb; V, Wb, and $\mathrm{T}$ for the volt, weber, and tesla; $\mathrm{F}$ and $\mathrm{S}$ for the farad and siemens; $\Omega$ and $\mathrm{H}$ for the ohm and henry; ${ }^{\circ} \mathrm{C}$ for the degree Celsius; and kat for the katal.

Although the widely used electron volt $\mathrm{eV}$ and (unified) atomic mass unit u are not SI units, they are accepted for use with the SI by the CIPM [2]; for completeness their expressions are indicated below in Eqs. (10i) and (10j) and are obtained in the following way. The eV is a unit of energy and is equal to $\{e\}_{C} \mathrm{~J}$ when expressed in the SI unit of energy, J, where $\{e\}_{C}=e / C$ is the numerical value of $e$ when expressed in the SI unit of charge, C. With the aid of Eq. (10b) we then obtain $(\mathrm{eV})_{\mathrm{rev}} /(\mathrm{eV})_{\mathrm{cur}}=$ $\{e\}_{\text {rev }}(\mathrm{J})_{\text {rev }} /\{e\}_{\text {cur }}(\mathrm{J})_{\text {cur }}=\{h / e\}_{\text {cur }} /\{h / e\}_{\text {rev }}$ Therefore,

$$
(\mathrm{U})_{\mathrm{rev}} /(\mathrm{U})_{\mathrm{cur}}=\{h / e\}_{\mathrm{cur}} /\{h / e\}_{\mathrm{rev}} \text { for } \mathrm{U}=\mathrm{eV} \text {. }
$$

The unit $\mathrm{u}=m_{\mathrm{u}}=m\left({ }^{12} \mathrm{C}\right) / 12$, where $m_{\mathrm{u}}$ is the atomic mass constant and $m\left({ }^{12} \mathrm{C}\right)$ is the mass of the carbon 12 atom, is a unit of mass. Because $\mathrm{u}=m\left({ }^{12} \mathrm{C}\right) / 12$ and $m\left({ }^{12} \mathrm{C}\right) / 12$ is a fixed constant with unit kg, Eqs. (3), (4), and (9c) yield $\left\{m\left({ }^{12} \mathrm{C}\right) / 12\right\}_{\mathrm{rev}}(\mathrm{kg})_{\mathrm{rev}}=\left\{m\left({ }^{12} \mathrm{C}\right) / 12\right\}_{\mathrm{cur}}(\mathrm{kg})_{\mathrm{cur}}$ or $(\mathrm{u})_{\mathrm{rev}} /(\mathrm{u})_{\mathrm{cur}}=(\mathrm{kg})_{\mathrm{cur}} /(\mathrm{kg})_{\mathrm{rev}}=\{h\}_{\mathrm{rev}} /\{h\}_{\mathrm{cur}}$ Therefore,

$$
(\mathrm{U})_{\mathrm{rev}} /(\mathrm{U})_{\mathrm{cur}}=\{h\}_{\mathrm{rev}} /\{h\}_{\mathrm{cur}} \text { for } \mathrm{U}=\mathrm{u} .
$$

Numerous derived SI units have no special names and symbols. However, they are typically combinations of derived units with special names and symbols and base units. Consequently, the expressions for the ratios of their revised SI magnitudes to their current SI magnitudes in terms of fundamental constants can be obtained using Eqs. (9a)-(9g) and (10a)-(10j). Many such ratios involve one base unit or one derived unit with a special symbol and either $\mathrm{m}$, s, or both and can be deduced by inspection. For example, the unit of momentum is $\mathrm{kg} \mathrm{m} \mathrm{s}^{-1}$, hence its ratio is that for $\mathrm{kg}$. Another is the unit for charge density $\mathrm{C} \mathrm{m}^{-3}$; its ratio is the same as that for $\mathrm{C}$. An example of a more complex unit is $\mathrm{W} \mathrm{m} \mathrm{m}^{-2} \mathrm{~K}^{-4}$, which is the unit of the Stefan-Boltzmann constant $\sigma$. From Eqs. (9e) and (10b) the ratio for this unit is $\left\{k^{4} / h^{3}\right\}_{\text {cur }} /\left\{k^{4} / h^{3}\right\}_{\text {rev. }}$

\section{Current SI Defining Constants Expressed in Revised SI Units}

Replacing the exactly known current SI defining constants $m(\mathcal{K})=1(\mathrm{~kg})_{\mathrm{cur}}, \mu_{0}=4 \pi \times 10^{-7}(\mathrm{H})_{\mathrm{cur}} \mathrm{m}^{-1}$, $T_{\mathrm{TPW}}=273.16(\mathrm{~K})_{\mathrm{cur}}$, and $M\left({ }^{12} \mathrm{C}\right)=12 \times 10^{-3}\left(\mathrm{~kg} \mathrm{~mol}^{-1}\right)_{\text {cur }}$ with the new SI defining constants $h, e, k$, and $N_{\mathrm{A}}$ 
means that the numerical values of $m(\mathcal{K}), \mu_{0}, T_{\mathrm{TPW}}$, and $M\left({ }^{12} \mathrm{C}\right)$ are no longer exactly known when these constants are expressed in their revised SI units. We show in this section how the quantity calculus can be used to obtain useful relationships for the four ratios $\{m(\mathcal{K})\}_{\text {rev }} /\{m(\mathcal{K})\}_{\text {cur, }}\left\{\mu_{0}\right\}_{\text {rev }} /\left\{\mu_{0}\right\}_{\text {cur }}$,

$\left\{T_{\mathrm{TPW}}\right\}_{\mathrm{rev}} /\left\{T_{\mathrm{TPW}}\right\}_{\mathrm{cur}}$, and $\left\{M\left({ }^{12} \mathrm{C}\right)\right\}_{\mathrm{rev}} /\left\{M\left({ }^{12} \mathrm{C}\right)\right\}_{\mathrm{cur}}$ as was done in Sec. 5 for base and derived units. Applying Eq. (3) to $m(\mathcal{K})$, the unit of which is $\mathrm{kg}$, one obtains

$$
m(\mathcal{K})=\{m(\mathcal{K})\}_{\mathrm{cur}}(\mathrm{kg})_{\mathrm{cur}}=\{m(\mathcal{K})\}_{\mathrm{rev}}(\mathrm{kg})_{\mathrm{rev}},
$$

implying

$$
\frac{\{m(\mathcal{K})\}_{\mathrm{rev}}}{\{m(\mathcal{K})\}_{\mathrm{cur}}}=\frac{(\mathrm{kg})_{\mathrm{cur}}}{(\mathrm{kg})_{\mathrm{rev}}},
$$

which becomes with the aid of Eq. (9c),

$$
\frac{\{m(\mathcal{K})\}_{\mathrm{rev}}}{\{m(\mathcal{K})\}_{\mathrm{cur}}}=\frac{\{h\}_{\mathrm{rev}}}{\{h\}_{\mathrm{cur}}} .
$$

The derivations of the other three defining-constant ratios follow the same pattern. The unit of $\mu_{0}$ is $\mathrm{H} \mathrm{m}^{-1}=\mathrm{N} \mathrm{A}^{-2}=\mathrm{kg} \mathrm{m}^{2} \mathrm{~s}^{-2} \mathrm{~A}^{-2}$. Consequently,

$$
\mu_{0}=\left\{\mu_{0}\right\}_{\mathrm{cur}}(\mathrm{kg})_{\mathrm{cur}} \mathrm{m}^{2} \mathrm{~s}^{-2}\left(\mathrm{~A}^{-2}\right)_{\mathrm{cur}}=\left\{\mu_{0}\right\}_{\mathrm{rev}}(\mathrm{kg})_{\mathrm{rev}} \mathrm{m}^{2} \mathrm{~s}^{-2}\left(\mathrm{~A}^{-2}\right)_{\mathrm{rev}},
$$

yielding

$$
\frac{\left\{\mu_{0}\right\}_{\text {rev }}}{\left\{\mu_{0}\right\}_{\text {cur }}}=\frac{(\mathrm{kg})_{\text {cur }}}{(\mathrm{kg})_{\text {rev }}} \frac{\left(\mathrm{A}^{2}\right)_{\text {rev }}}{\left(\mathrm{A}^{2}\right)_{\text {cur }}},
$$

or together with Eqs. (9c) and (9d)

$$
\frac{\left\{\mu_{0}\right\}_{\mathrm{rev}}}{\left\{\mu_{0}\right\}_{\mathrm{cur}}}=\frac{\left\{h / e^{2}\right\}_{\mathrm{rev}}}{\left\{h / e^{2}\right\}_{\mathrm{cur}}} .
$$

The unit of $T_{\mathrm{TPW}}$ is $\mathrm{K}$, implying

$$
T_{\mathrm{TPW}}=\left\{T_{\mathrm{TPW}}\right\}_{\mathrm{cur}}(\mathrm{K})_{\mathrm{cur}}=\left\{T_{\mathrm{TPW}}\right\}_{\mathrm{rev}}(\mathrm{K})_{\mathrm{rev}},
$$

or

$$
\frac{\left\{T_{\mathrm{TPW}}\right\}_{\mathrm{rev}}}{\left\{T_{\mathrm{TPW}}\right\}_{\mathrm{cur}}}=\frac{(\mathrm{K})_{\mathrm{cur}}}{(\mathrm{K})_{\mathrm{rev}}},
$$

which together with Eq. (9e) can be written as

$$
\frac{\left\{T_{\mathrm{TPW}}\right\}_{\mathrm{rev}}}{\left\{T_{\mathrm{TPW}}\right\}_{\mathrm{cur}}}=\frac{(k / h)_{\mathrm{cur}}}{(k / h)_{\mathrm{rev}}} .
$$

And finally, the unit of $M\left({ }^{12} \mathrm{C}\right)$ is $\mathrm{kg} \mathrm{mol}^{-1}$, hence

$$
M\left({ }^{12} \mathrm{C}\right)=\left\{M\left({ }^{12} \mathrm{C}\right)\right\}_{\text {cur }}(\mathrm{kg})_{\mathrm{cur}}\left(\mathrm{mol}^{-1}\right)_{\mathrm{cur}}=\left\{M\left({ }^{12} \mathrm{C}\right)\right\}_{\mathrm{rev}}(\mathrm{kg})_{\mathrm{rev}}\left(\mathrm{mol}^{-1}\right)_{\mathrm{rev}},
$$

resulting in

$$
\frac{\left\{M\left({ }^{12} \mathrm{C}\right)\right\}_{\mathrm{rev}}}{\left\{M\left({ }^{12} \mathrm{C}\right)\right\}_{\mathrm{cur}}}=\frac{(\mathrm{mol})_{\mathrm{rev}}}{(\mathrm{mol})_{\mathrm{cur}}} \frac{(\mathrm{kg})_{\mathrm{cur}}}{(\mathrm{kg})_{\mathrm{rev}}}
$$

or in combination with Eqs. (9c) and (9f),

$$
\frac{\left\{M\left({ }^{12} \mathrm{C}\right)\right\}_{\mathrm{rev}}}{\left\{M\left({ }^{12} \mathrm{C}\right)\right\}_{\mathrm{cur}}}=\frac{\left\{N_{\mathrm{A}} h\right\}_{\mathrm{rev}}}{\left\{N_{\mathrm{A}} h\right\}_{\mathrm{cur}}} .
$$




\section{Conclusion}

The quantity calculus is a valuable tool as clearly demonstrated by its use to obtain the 35 expressions in Eqs. (5a)-(5g) through (9a)-(9g), the 24 expressions represented by Eqs. (10a)-(10j), and the four expressions in Eqs. (11a)-(11d). The ratios in these last four expressions, namely, $\{m(\mathcal{K})\}_{\text {rev }} /\{m(\mathcal{K})\}_{\text {cur }}$, $\left\{\mu_{0}\right\}_{\text {rev }} /\left\{\mu_{0}\right\}_{\text {cur }},\left\{T_{\mathrm{TPW}}\right\}_{\text {rev }} /\left\{T_{\mathrm{TPW}}\right\}_{\text {cur, }}$ and $\left\{M\left({ }^{12} \mathrm{C}\right)\right\}_{\mathrm{rev}} /\left\{M\left({ }^{12} \mathrm{C}\right)\right\}_{\text {cur }}$, played an important role in choosing the exact numerical values for the four revised SI defining constants $h, e, k$, and $N_{\mathrm{A}}$, starting from their current values from the CODATA 2017 Special Adjustment. This is because the CIPM decided that adequate consistency between the revised SI and the current SI could be achieved if the minimum number of digits for each exactly defined revised SI defining constant $h, e, k$, and $N_{\mathrm{A}}$ were chosen such that each of these ratios is equal to 1 within its standard uncertainty [10]. As given in Ref. [7], these uncertainties are $1.0 \times 10^{-8}, 2.3 \times 10^{-10}, 3.7 \times 10^{-7}$, and $4.5 \times 10^{-10}$, respectively. As a result of this choice, all of the base-unit ratios and derived-unit ratios as given in Eqs. (9a)-(9g) and Eqs. (10a)-(10j) are equal to 1 with comparably small uncertainties, thereby further demonstrating the consistency of the revised SI with the current SI. Consequently, on the 20 May 2019 planned starting date for the revised SI chosen by the CIPM [12], the transition from the current SI to the revised SI is expected to occur seamlessly.

Indeed, this choice of starting date is quite fitting because 20 May 2019 is World Metrology Day. Celebrated annually, it was on this day in 1875 that representatives of seventeen nations meeting in Paris signed the Meter Convention that created the CGPM, CIPM, and BIPM. The international prototype of the kilogram has been superbly maintained at the BIPM since it was sanctioned as the unit of mass by the 1st CGPM in 1889 [1], but its historic role will now end on this date after 130 years!

\section{References}

[1] Taylor BN (2011) The Current SI Seen From the Perspective of the Proposed New SI. J Res Natl Inst Stan 116(6):797-807. https://doi.org/10.6028/jres.116.022

[2] BIPM (2006) International System of Units (SI) (Bureau International des Poids et Mesures, Sèvres, France), 8th ed., ISBN 92822-2213-6. Available at https://www.bipm.org/utils/common/pdf/si_brochure_8_en.pdf Supplement 2014: Updates to the 8th Edition (2006) of the SI Brochure. Available at https://www.bipm.org/utils/common/pdf/si_supplement_2014.pdf

[3] BIPM (2018) International Bureau of Weights and Measures (BIPM) Web site. Available at https://www.bipm.org/en/measurement-units/rev-si/

[4] CGPM (2011) Resolution 1 of the 24th CGPM. Available at https://www.bipm.org/en/CGPM/db/24/1/

[5] CGPM (2014) Resolution 1 of the 25th CGPM. Available at https://www.bipm.org/en/CGPM/db/25/1/

[6] Newell DB, Cabiati F, Fischer J, Fujii K, Karshenboim SG, Margolis HS, de Mirandés E, Mohr PJ, Nez F, Pachucki K, Quinn TJ, Taylor BN, Wang M, Wood BM, Zhang Z (2018) The CODATA 2017 values of $h, e, k$, and $N_{\mathrm{A}}$ for the revision of the SI. Metrologia 55(1):L13-L16. https://doi.org/10.1088/1681-7575/aa950a

[7] Mohr PJ, Newell DB, Taylor BN, Tiesinga E (2018) Data and analysis for the CODATA 2017 special fundamental constants adjustment. Metrologia 55(1):125-146. https://doi.org/10.1088/1681-7575/aa99bc

[8] CIPM 2015 Decision CIPM/104-09 of the 104th CIPM, Session I. Available at https://www.bipm.org/en/committees/cipm/meeting/104(I).html

[9] CIPM 2017 Decisions CIPM/106-10, -11, -12 of the 106th CIPM. Available at https://www.bipm.org/en/committees/cipm/meeting/106.html

[10] CIPM 2016 Decision CIPM/105-15 of the 105th CIPM. Available at https://www.bipm.org/en/committees/cipm/meeting/105.html This decision adopts Case III in Table 2 of document CCU/16-29 by D. B. Newell and B. N. Taylor entitled "On choosing the number of digits for the numerical values of the New SI defining constants $h, e, k$, and $N_{\mathrm{A}}$." Submitted to the 22nd meeting of the Consultative Committee for Units (CCU) of the CIPM, June 2016, it is not publicly available. Case III is the minimum number of digits for each value of $h, e, k$, and $N_{\mathrm{A}}$ such that each ratio of the numerical value of $m(\mathcal{K}), \mu_{0}, T_{\mathrm{TPW}}$, and $M\left({ }^{12} \mathrm{C}\right)$ expressed in its revised SI unit to its exact current SI numerical value is equal to 1 within its standard uncertainty.

[11] CIPM 2017 Decisions CIPM/106-10, -11, -12 of the 106th CIPM. Available at https://www.bipm.org/en/committees/cipm/meeting/106.html

[12] CIPM 2016 Decision CIPM/105-13 of the 105th CIPM. Available at https://www.bipm.org/en/committees/cipm/meeting/105.html

[13] Solve S, Chayramy R, Maruyama M, Urano C, Kaneko NH, Rüfenacht A (2018) Direct DC 10 V comparison between two programmable Josephson voltage standards made of niobium nitride ( $\mathrm{NbN}$ )-based and niobium (Nb)-based Josephson junctions. Metrologia 55(2):302-313. https://doi.org/10.1088/1681-7575/aaac44

[14] Mohr PJ, Newell DB, Taylor BN (2016) CODATA recommended values of the fundamental physical constants: 2014. Reviews of Modern Physics 88(3):035009-1-035009-73. https://doi.org/10.1103/RevModPhys.88.035009 
[15] Mohr PJ, Newell DB, Taylor BN (2016) CODATA Recommended Values of the Fundamental Physical Constants: 2014. Journal of Physical and Chemical Reference Data 45(4):043102-1-043102-74. https://doi.org/10.1063/1.4954402

[16] ISO (1995) Guide to the Expression of Uncertainty in Measurement (International Organization for Standardization [ISO], Geneva, Switzerland), 1st ed., Corrected and Reprinted, 1995, ISBN 92-67-10188-9. This publication, commonly referred to as the GUM, is available with minor corrections at https://www.bipm.org/utils/common/documents/jcgm/JCGM_100_2008_E.pdf

About the author: Barry N. Taylor, a physicist, is a NIST Scientist Emeritus in the Fundamental Constants Data Center (FCDC), Quantum Measurement Division (QMD), Physical Measurement Laboratory (PML). He retired in 2001 after nearly 31 years at NIST and its predecessor, the National Bureau of Standards (NBS). He has continued his previous work on periodic adjustments of the values of the fundamental constants and providing the international community with self-consistent sets of recommended values of the constants through CODATA. He has been actively involved for nearly the past 20 years in the international effort to establish a revised SI. He was a major contributor to the Guide to the Expression of Uncertainty in Measurement (GUM) during the first half of the 1990s.

The National Institute of Standards and Technology is an agency of the U.S. Department of Commerce. 